\title{
Cholesterol Concentrations in Diabetic Patients in Nnewi, Nigeria
}

\author{
Joseph Eberendu Ahaneku ${ }^{1,2}$, Chukwudi Emmanuel Dioka ${ }^{2}$ and Joseph Ndefo ${ }^{3}$ \\ ${ }^{1}$ Department of Biochemistry, Saga Medical School, Nabeshima, Saga 849, Japan \\ 2 Department of Chemical Pathology, Nnamdi Azikiwe University Teaching Hospital Nnewi, \\ Nnewi, Anambra State, Nigeria \\ ${ }^{3}$ Department of Medical Microbiology, Nnamdi Azikiwe University Teaching Hospital Nnewi, \\ Nnewi, Anambra State, Nigeria
}

Summary: Twenty out-patient and twenty in-patient adult Nigerian type II diabetics and twenty healthy subjects matched for sex, age and weight, were studied at Nnamdi Azikiwe University Teaching Hospital, Nnewi, Nigeria. Mean total cholesterol and fasting blood glucose concentrations were higher in the diabetics. The out-patients had significantly higher total cholesterol and fasting blood glucose values than their in-patient counterparts. The possible cardiovascular risk of the raised cholesterol level in the diabetics was discussed. We recommend that for effective management of diabetic patients, periodic measurement of cholesterol level is necessary. An integrated enlightenment programme to acquaint the out-patients with the health benefits of dietary and drug compliance and occasional hospitalisation for better monitoring would be desirable.

\section{Introduction}

In diabetic patients, macrovascular disease accounts for the majority of all deaths, mainly in the form of cardiovascular disease (1). Irrespective of the well known heterogeneity in the aetiology of diabetes, the propensity of macrovascular complication is not restricted to any particular type of diabetes $(2,3)$. Furthermore, clinically significant atherosclerotic lesions were found to be unassociated with the duration or severity of overt diabetes; they were rather a feature of individuals with relatively mild diabetes (4-6). Meanwhile, clinical and histopathological evidence of accelerated atherosclerosis has been documented in insulin-dependent diabetics (7). Hyperlipidaemia is a common complication among diabetics. The most commonly known lipid abnormality in diabetics is hypertriglyceridaemia, and not an increase in total cholesterol $(8-10)$. However, elevation of the total cholesterol level (an independent cardiovascular risk factor) (11) has been reported in certain populations of patients $(12-14)$.

In the present study, our subjects were drawn from a sub-urban commercial area. We determined, for the first time, the serum cholesterol levels in the diabetic patients from this community, and excluded the possible influence of other risk factors such as obesity, smoking and alcoholism through interview assessment. In addition, this study is expected to provide data that would discriminate between the in-patient and out-patient diabetics with respect to the level of the complicating factor, hypercholesterolaemia; this will form a basis for the better management and/or follow-up of patients by clinicians.

\section{Patients, Materials and Methods}

Selection of patients and control subjects

Forty diabetic patients of both sexes, aged $40.0 \pm 3.2$ years (mean \pm SEM) and twenty apparently healthy subjects matched for age and sex were selected for this study at Nnamdi Azikiwe University Teaching Hospital, Nnewi, Nigeria. The diabetic patients consisted of twenty out-patients and twenty in-patients (10 males and 10 females in each case). The diagnosis of diabetes was established by clinical examinations and laboratory analyses of two hours postprandial blood glucose level, oral glucose tolerance test with $75 \mathrm{~g}$ glucose load and fasting blood glucose levels. The patients were type II diabetics (non-insulin-dependent diabetes mellitus), and the duration of diabetes ranged between 1 and 3 years; in all patients, diabetes onset occurred in adulthood. The out-patients were treated with Glipizide (GLUCOTROL), a member of the sulfonylurea group of hypoglycaemic agents, in doses of 5 and $10 \mathrm{mg}$ tablets daily plus a recommended diabetic diet (same diet as given to the in-patients in the hospital). Patients were monitored every fortnight in the ambulatory state. The in-patients were hospitalised for 2-4 weeks and treated with Glipizide like their out-patient counterparts plus the compulsory diabetic diet served in the hospital, which contained high levels of plant protein (beans), plantain and vegetables, and low carbohydrate.

The control subjects consisted of ten male and ten female staff volunteers from our teaching hospital and the local government secretariat office. The patients and controls were all Nigerians and oral and written consent were given before selection into the study.

Routine medical examinations and interviews were carried out in order to eliminate the presence of other diseases and risk factors in all the patients and controls. The patients (diastolic blood pressure $=81 \pm 0.8 \mathrm{~mm} \mathrm{Hg}$ mean $\pm \mathrm{SEM}$ ) and controls (diastolic blood pressure $=80 \pm 0.9 \mathrm{~mm} \mathrm{Hg}$ mean \pm SEM) were non-hypertensives as confirmed by the World Health Organisation criteria for mild to moderate hypertension (15), non-obese, non-smokers 
and non-consumers of alcoholic beverages. The female patients and controls were neither pregnant nor lactating, and they were not on oral contraceptives.

Measurement of physical variables, sample collection, glucose and cholesterol assays

Following selection into the study, the weight of each subject was taken with an electronic weighing scale. Level of obesity was determined in each patient or control by body mass index. Body mass index was calculated as weight/height ${ }^{2}\left(\mathrm{~kg} / \mathrm{m}^{2}\right)$, and subjects with body mass index values of above 25 were regarded as obese (16). A standard format was adopted to measure cigarette smoking and alcohol consumption.

Venous blood $(10 \mathrm{ml})$ was withdrawn from each subject (both patients and controls) after an overnight fast of 10-12 hours. An aliquot of $2 \mathrm{ml}$ for glucose analysis was collected into a container with sodium fluoride as the anticoagulant. The remaining $8 \mathrm{ml}$ intended for cholesterol analysis was collected into a plain bottle and allowed to clot; thereafter the serum was separated for cholesterol assay. Fasting blood glucose was determined by the method of Trinder (17). Plasma cholesterol was determined by the modified Liebermann-Burchard reaction as described by Searcy \& Berquist (18). The fasting blood glucose and total cholesterol assays were standardised and quality controlled by using pooled sera and commercial Wellcomtrol one and two reagents of known values. The patients and the controls were of the same socio-economic background.

\section{Statistical analysis}

Analysis of variance was used to assess the variability between and within the in-patients and out-patients, and the control subjects. The statistical significance of differences between the mean values of fasting blood glucose and cholesterol for the in-patient and outpatient diabetics and the control subjects were determined by a two-tailed Student t-test.

\section{Results}

As shown in figure 1a, the out-patient $(\mathrm{P}<0.001)$ and in-patient $(\mathrm{P}<0.01)$ diabetics had significantly higher fasting blood glucose concentrations when compared with the control subjects. The mean fasting blood glu-

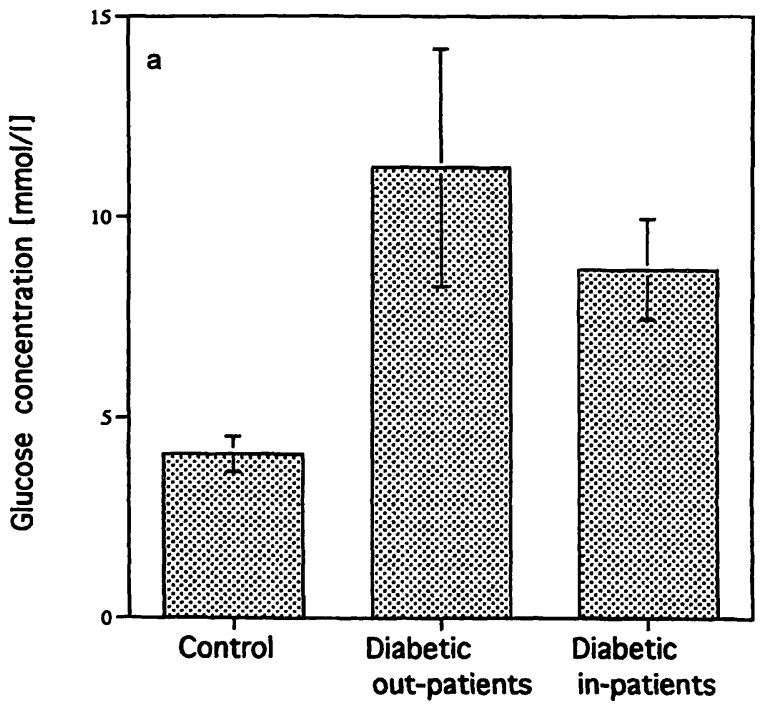

Fig. 1a Comparison of fasting blood glucose levels between diabetic patients and healthy subjects.

control vs diabetic out-patients $=\mathrm{P}<0.001$;

control vs diabetic in-patients $=\mathrm{P}<0.01$;

diabetic out-patients vs diabetic in-patients $=\mathrm{P}<0.05$. cose concentration of the out-patient was also significantly higher $(P<0.05)$ than that of the in-patient diabetics.

Similarly, the mean total cholesterol concentrations of the out-patient and in-patient diabetics were significantly higher $(P<0.001$ and $P<0.05$, respectively) when compared with the corresponding control values (fig. 1b). The difference in the mean total cholesterol value between the out-patient and in-patient diabetics, was also significant $(P<0.05)$.

\section{Discussion}

The observed increase in the fasting blood glucose in the diabetics was expected and the significant rise in total cholesterol concentration in the diabetic patients in this study is consistent with the findings reported by previous workers $(12-14)$, but disagrees with others $(8-9)$ who reported hypertriglyceridaemia as the main lipid abnormality in their diabetic patients. Furthermore, we observed that the mean total cholesterol level of our out-patients was significantly higher than the value for the in-patient diabetics. The mean total cholesterol level $(7.3 \pm 1.6 \mathrm{mmol} / \mathrm{l})$ of the out-patient diabetics was almost two-fold higher than that of the control subjects $(4.8 \pm 0.68 \mathrm{mmol} / \mathrm{l})$, and quite above the normal reference range for total cholesterol $(2.5-5.7 \mathrm{mmol} / \mathrm{l})$ in the Nigerian population. The mean total cholesterol level of $(5.5 \pm 0.96 \mathrm{mmol} / \mathrm{l})$ for the in-patients, though significantly higher than that of control subjects, falls within the upper limits of the normal reference range for total cholesterol of the entire Nigerian population. Raised cholesterol has long been recognised as a potent risk factor for the development of coronary heart disease

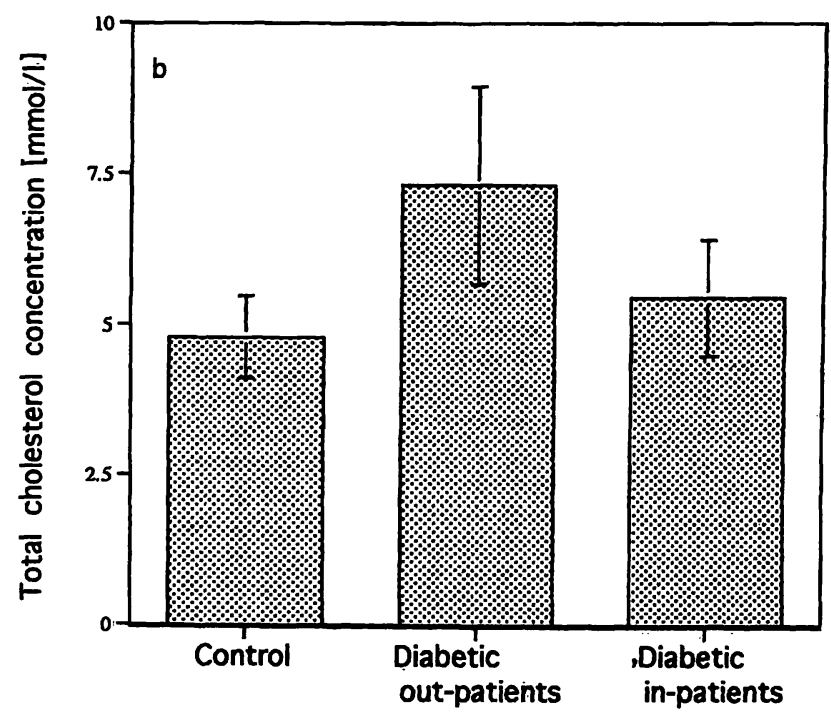

Fig. 1b comparison of total cholesterol levels between diabetic patients and healthy subjects.

control vs diabetic out-patients $=\mathrm{P}<0.001$;

control vs diabetic in-patients $=\mathrm{P}<0.05^{\circ}$

diabetic out-patients vs diabetic in-patients $=\mathrm{P}<0.05$. 
$(13-14,19)$. Thus, it is pertinent to say that all the diabetic patients in this study were exposed to a higher risk of coronary heart disease viz-a-viz the co-existence of hyperglycaemia and hypercholesterolaemia. Meanwhile, the risk of coronary heart disease was even higher in the out-patient diabetics, thereby making their condition more precarious. It was not surprising that the blood glucose level of the out-patients was poorly controlled, because these patients may have defaulted in the dietary and drug prescriptions, unlike their in-patient counterparts who were under close monitoring by the physician. The out-patients in their homes may have been enjoying the normal Nigerian diet which consists mainly of high carbohydrate, low protein and vegetable meal, and this differs a little in terms of percentage micronutrients from the recommended diabetic diet (served in the hospital) as described earlier in the text. Most of the patients studied had a low level of education (mainly primary school level); this factor compounded their problem be-

\section{References}

1. Marble A. Late complication of diabetes: a continuing challenge. Diabetologia 1976; 12:193-9.

2. Ganda OP, Soeldner JS. Genetic, acquired and related factors in the etiology of diabetic mellitus. Arch Intern Med 1977; 137:461-9.

3. Pyke DA. Diabetes: the genetic connections. Diabetologia 1979; 17:333-43.

4. Bradley RF. Cardiovascular disease. In: Marbel A, White P, Bradley RF, Krall LP, editors. Jostin's diabetes mellitus. Philadelphia: Lea and Febiger, 1971:417-77.

5. Kannel WB, McGee DL. Diabetes and cardiovascular disease. The Framingham study. J Am Med Ass 1979; 241:2035-8.

6. Keen $\mathrm{H}$. Glucose intolerance, diabetes mellitus and atherosclerosis; prospects for prevention. Postgrad Med J 1976; 52:445-51.

7. Crall VF Jr, Roberts WC. The extramural and intramural coronary arteries in juvenile diabetes mellitus. Analysis of nine necropsy patients aged $19-38$ years with onset of diabetes before age 15 years. Am J Med 1978; 64:221-30.

8. Jarvett RJ. Diabetes and the heart: coronary heart disease. Clin Endocrinol Metab 1977; 6:389-402.

9. Tzagouriris $M$. Interaction of diabetes with hypertension and lipids - patients at high risk. Am J Med 1989; 86 Suppl lb: $50-4$.

10. Brunzel JD, Beiermann EL. Pathophysiology of liproprotein transport. Metabolism 1978; 27:1109-27.

11. Lipid Research Clinics Programme. The lipid research clinics coronary primary prevention trial results: II. The relationship of reduction in incidence of coronary heart disease to cholesterol lowering. J Am Med Ass 1984; 251:365-74.

12. Albrink MJ, Lavietes PH, Man EB. Vascular disease and serum lipids in diabetes mellitus. Observations over thirty years (1931-1961). Ann Intern Med 1963; 58:305-23. cause these patients could not actually appreciate the health hazards associated with non-compliance with their diet and antidiabetic drugs. It is possible that nonregulation of dietary fat and carbohydrate intake may have contributed to the higher levels of total cholesterol in the out-patients (20). Thus, we recommend that for effective management of diabetic patients with a background similar to the one described here, periodic measurement of cholesterol level is necessary. An integrated programme to educate the patients about the health benefits of compliance with their dietary and drug therapies will be desirable. Occasionally, the out-patients may be required to undergo hospital admission for better monitoring and management.

In general, these findings should assist diabetologists and other physicians in the effective management of diabetic patients with similar backgrounds to those in this study.

13. Kannel WB, Castelli WB, Gordon T, McNamara PM. Serum cholesterol, lipoproteins and the risk of coronary heart disease. The Framingham study. Ann Intern Med 1971; 74:1-12.

14. Cohn PF, Gabbay SI, Weglicki WB. Serum Lipid levels in angiographically defined coronary artery disease. Ann Intern Med 1976; 84:241-5.

15. Ahaneku JE, Agbedana EO, Taylor GO. Relationship between Body Mass Index (BMI) and changes in plasma total and HDL-cholesterol levels during treatment of hypertension in African patients. Acta Med Okayama 1995; 49(5):26770.

16. Anders RD, Elahi JD, Tobin DC, Muller LB. Impact of age on weight goals. Ann Intern Med 1985; 103 (6pt2):1030-3.

17. Trinder P. Blood glucose method by glucose oxidase using 4aminophenazone as oxygen acceptor. J Clin Pathol 1969; 22:246.

18. Searcy RL, Berquist LM. A new colour reaction for the quantitation of serum cholesterol. Clin Chim Acta 1960; 5:192-9.

19. Ross R. The pathogenesis of atherosclerosis - An update. New Engl J Med 1986; 314:488-500.

20. Ida Chen YD, Swani S, Skowronski R, Coulston AM, Reaven GM. Effects of variations in dietary fat and carbohydrate intake on postprandial lipemia in patients with non-insulin-dependent diabetes mellitus. J Clin Endocrinol Metab 1993; $76(2): 347-51$.

Received June 21/December 11, 1995

Corresponding author: Dr. J. E. Ahaneku, Department of Chemical Pathology, Nnamdi Azikiwe University Teaching Hospital Nnewi, P.M.B. 5025 Nnewi, Anambra State, Nigeria 
